\title{
Practice of Medicine.
}

dicines, when requisite. Dr. $\mathbf{S}$. mentions the case of a man, who had suffered for many months from dropsy, his abdomen being very tumid and undulating; urine scanty; extremities cedematous; countenance bloated, and skin harsh and its diuretic effects so freely, that a was applied over each kidney, and produced to the interruption of rest. had decreased a foot: the dropsy days the circumference of the man's belly The remedy was used in July, 1829, cured, and the man's health restored. heard from, sixteen months after. sarca, the symptoms of which wer. The $2 \mathrm{~d}$ case was a Dragoon, who had anaand the man died; when the were speedily removed, but the disease returned, with disease of the heart with benefit; but the patient at the same time; therefore, the not under his care, and used other medicines case. The Lichen vulgaris is com effects of the remedy might be doubtful in that and the lower branches and denuonly found in the Deckan, growing on rocks, the Medical and Physical Society of Calcutta, $V_{0} l . V$.

11. Remarks on the Medical Properties of the Haritakee, or Myrobalan. Translated from several Native Medical Works, by RAJAH KALIKIssex, and read at the Medical Society's Meeting, on the ?th of May, 1831. - The fruit of the Terlish, is much used as a named Haritakee in Bengal, and Myrobalan in Enging and administering this medicine the natives of India: their modes of preparis varied according to the season of the its combination with other substances, the effect intended to be produced of the year in which it is administered, and ed medicinally; that chiefly in use, is the smal kinds of the haritakee are employin Bengallee, Jungeia haritakee. It is conill black myrobalan, which is called rately warm description, which has some with great advantage in many chronic tions, improve the general health, and complaints. It is said to remove obstrucous disorders, and hypochondriacal affectiongthen the digestion; relieving bililife." A regular course of this medicine is, and " increasing the happiness of ducing the above effects; and it is recome is prescribed for the purpose of promonths. By this account, haritakee Mr. Abernethy's blue pill system, seems to produce all the good effects of out any of the evil consequences freques many others of great benefit; withtracted use of mercurial preparations. The arising from the habitual and proextolled, that it seems well worthys. The efficacy of this medicine is so much been impaired for a long time; and of a trial on Europeans, whose health has referred to weak digestion, torpid bspecially where the principal disorder is with lowness of spirits, and emaciationels, bilious disorder, and general debility; grains of the black myrobalan in pow. As an aperient, the usual dose is twenty ed every morning. In protracted chronic, with ten grains of black sult, repeattinued for three months: during the first salt as above stated, during the second month, the combination with black ten grains of brown Jagry sugar, are ordered to be taken every day; and for
the third month, twenty grains of haritakee, with and ten grains of caraway seeds in powder. with ten grains of common salt,

\section{PRACTICE OF MEDICINE.}

12. Treatment of Gastrodynia of Dr. Gruves. - Sept. 1828. Rev. I. Drt. 36 , rather corpulent, of temperate habits, has suffered for three years from violent attacks of gastrodynia. They last sometimes for forty-eight hours, and during their continuance the agony is described to be so great as to make even 